\title{
ISOLATED RIGHT VENTRICULAR DILATED CARDIOMYOPATHY
}

\author{
(A Case Report)
}

\section{Maj RG PODUVAL", Maj VIKAS DHANORKAR ${ }^{+}$}

M.JAFI 1997: $53: 228-230$

KEYWORDS: Cardiomyopathy: Heart disease; Right ventricle.

\section{Introduction}

D ilated cardiomyopathy normally involves the left ventricle with some dysfunction of the right ventricle and the common clinical presentation is congestive cardiac failure. Isolated right ventricular dilated cardiomyopathy (RVDCM) presents as ventricular tachycardia and sometimes as sudden cardiac death. There is a paucity of clinical findings in RVDCM and the patient is asymptomatic when the rhythm is normal. The diagnosis is hence easily missed. Here we discuss a case where the presentation was with sudden onset ventricular achycardia and syncope without congestive symptoms. The diagnosis was made on echocardiography which revealed dilated, hypokinetic right ventricle, with normal left ventricular dimensions and ejection fraction.

\section{Case Repont}

A 47-yeatrodd mate patent had a syoupal attack doring physical training. He gave no history of cardiowascular illness in the past. After he regained consciousness he complained of postural diziness and while undergoing first aid for abrasions he was found to have tachycardia ( $>150 / \mathrm{min}$ ), low sustolic blood pressure and cannon waves in the neck veins. There was mild hepatomegaly and pedal edema. Ilowever, paticnt had no symptoms of congestive cardiac liailure. In the intensive care unit electrocardiogram slowed ventricular tachycardia with a rate of 190/min (Fig 1). As systemic hypotension persisted $D C$ cardioversion was done with 25 joules follow ing which normal sinus rhythm began (fig 2). The resting electrocardiogram showed clockwise rotation with no other abmornality and on the chest radiograph moderale cardiomegaly (CT ratto 15.28 ) with right ventricular conliguration was seen. lichocardiography showed right ventricular and right atrial dilation (right ventricular internal dimension $5.3 \mathrm{~cm}$ ). thin right ventricular wall with normal cello texture. and right ventricular hypokinesia. There was no obliteration of the right or left ventricular apex. The keft ventriche and the lelt altium were normal (left ventricular internal dastolic dimonsion $4.2 \mathrm{~cm})$. and the leli ventricle ejection fraction 81 per cent. The tricuspid valve was structurally normal. mifd trickspid regurgitation was present and the peak pulmonary ancer systolic pressure ealculated torm the

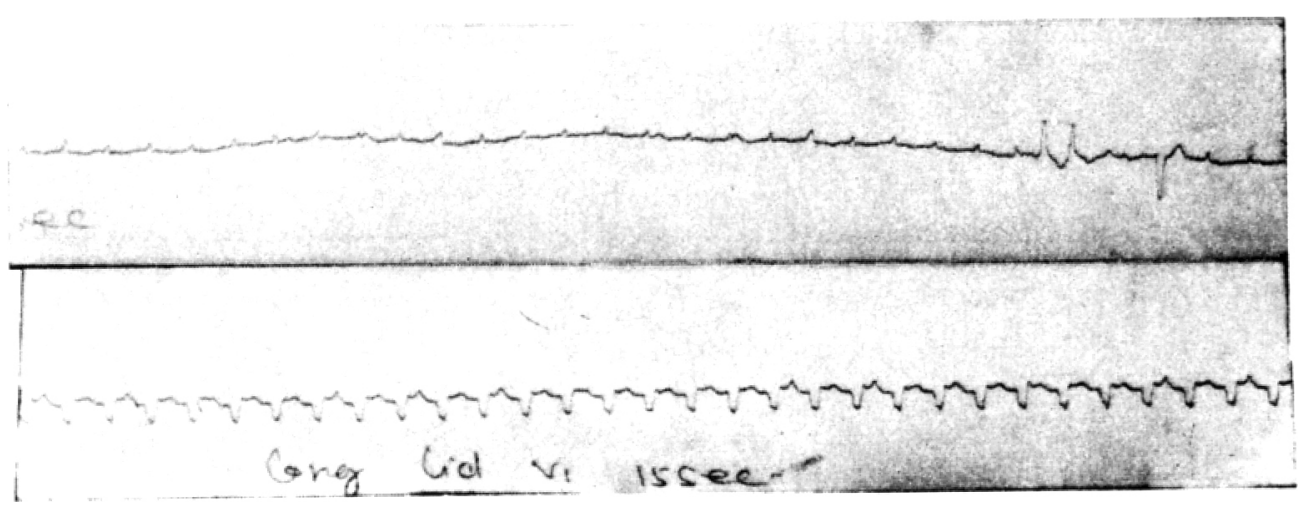

Fig. I: lici slow ing ventricular tachycardia with capture bealis.

"Classitied Specialist (Medicine). 153 General thospital, (\% 56 APO; "Medical Officer, NC(: Ofticers Training School, Kamptee 441001 . 


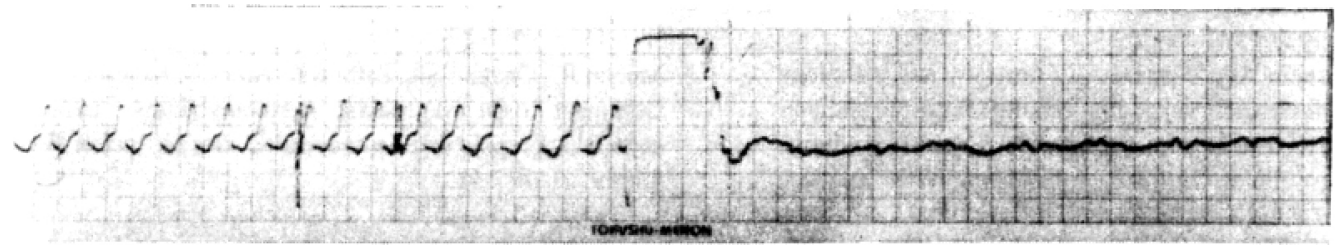

Fis. 2: Monitor strip showing restination al sinus rhythm with DC shock

regurgitant jet was $21 \mathrm{mml}$.g. thus sxcluding significant pulmonary arterial hypertension. On the basis of echocardiographic lindings he was diagnosed as a case of right ventricular dilated cardiomyopathy (RVDCM). He was advised to undergo, hemodynamic studics and endomyocardial biopsy but he was unwilling for any interventional prosedures and long-term antiatrhythmic and antiplatelet therapy were instituted

\section{Discussion}

In dilated cardiomyopathies biventricular involvement is the usual case though left ventricular dysfunction is more apparent. In RVDCM, as the name suggests. right ventricle is solely involved and left ventricular function is nomal. To recapitulate, the other causes of primary right huart failure are right ventricular infarction, tricuspid valve disease (rheumatic, infective endocarditis, Ebstein's anomaly, and carcinoid syndrome), and pulmonary valve disease (congenital pulmonic stenosis and rarely pulmonary regurgitation without pulmonary hypertension) [1]. RVDCM most often announces itself with ventricular tachycardia rather than as congestive cardiac failure. A male preponderance is seen and the most common clinical presentation is syncope or sudden death in young, otherwise, healthy men [2]. Thus unexplained ventricular tachycardia should raise the possibility of RVDCM as signs of systemic congestion are minimal and the diagnosis casily missed. In a recent study of sudden cardiac death anong healthy young athletes right ventricutar cardiomyopathy was the most common cause followed by hypertrophic cardiomyopathy and coronary artery anomalies [3]. The ventricular tachycardia has left bundle branch block pattern (ectopic focus in right ventricle) and the sinus rhythm electrocardiogram shows low voltage complexes reflecting the extent of right ventricular dilatation [4]. Cardiomegaly with right ventricular dominance is seen on chest radiograph and echocardiography reveals normal left ventricle with a poorly contractile and dilated right ventricle. On myocardial biopsy fibrosis and hypertrophy are seen.

Two conditions which closely resemble RVDCM are arrhythmogenic right ventricular dysplasia and right ventricular endomyocardial fibrosis. Arrhythmogenic right ventricular dysplasia which also presents as ventricular tachycardia is now considered a separate entity from RVDCM. The former is characterised by infundibular dyskinesia. aneurysm of the inferior or lateral wall, diastolic bulging below the tricuspid valve and highly refractile papillary muscle [5]. In endomyocardial fibrosis there is fibrotic obliteration of right ventricular apex and extension of the fibrosis back along the inflow tract to encase the papillary muscles [6]. Uhl's anomaly is a form of RVDCM which presents as cyanosis, congestive cardiac failure and death in infants. Here the myocardium is hypoplastic or aplastic (parchment heart of Osler).

The etiology of RVDCM is ill understood. Heredofamilial basis has been established. In experimental studies coxsackic virus infection can produce RVDCM. No causal relationship has been linked with alcohol or any specilic dictary deficiency. RVDCM in our country usually present with congestive symptoms and supraventricular tachycardia unlike the British variety in which ventricular tachycardia is more common [5]. This case was atypical for the lndian series and presented with ventricular tachycardia.

Treatment of RVDCM is directed towards prevention of ventricular arrhytlunias and sudden death. This is in contrast to other cardiomyopathies were afterload reduction and improvement in systolic function is ained for. Prophylactic antiarrhythmic drugs which are useful in RVDCM are propranolol and amiodarone. Internal defibrillator implantation and electrode ablation of ectopic focus are employed for recurrent and resistant ventricular tachyarrhythmias [7]. 


\section{REFERENCES}

1. Farb A. Burke AP, Virmani AR. Anatomy and pathology of the right ventricle (including acquired tricuspid and putmonic valve disease). In: Remetz MS, Cabin HS, editors. Cardiology clinics. Vol 10. Philadelphia: WB Saunders, 1992: 1-17.

2. Fitchett DH, Sugrue DD, MacArthur CG, Okley CM. Right ventricular dilated cardiomyopathy, Br Heart J 1984: $25 \cdot 9$.

3. Pelliccia A, Maron BJ. Preparticipation cardiovascular evaluation of the competitive athlete: Perspectives from the 30 year Italian experience. Am J Cardiol 1995; 75: 827-9.

4. Lidquyist $C$, Sabel $K G$, Olssom SB. A long term follow-up of IS patients with arthythmogenic ventricular dysplasia.
Br Heart J 1987; 58: 477-8

5. Mohan JC, Chutani SK, Sethi KK, Arora R, Khalliullah M. Dominant right ventricular cardiomyopathy. Clinical, echocardiographic and bemodynamic profile. Indian Heart J 1989; 4I: 177-81

6. Jhonson RA, Fifer MA, Palcios IF. Dilated and restrictive cardiomyopathies. In: Fagle KA, Hebert $E$, editors. The practice of cardiology. 2nd ed. Boston: Little Brown, 1980; 932-5.

7. Joshua $W$, Braunwald E. The cardiomyopathies and myocarditides. In: Braunwald $E$, editor. Heart diseases. A textbook of cardiovascular medicine. 3rd ed. Philadelphia: WB Saunders. 1988: 1416-7. 